Prince Albert and MacDowall. ${ }^{3}$ In Manitoba it has been found in the southcentral region in three localities, Grandview (1950), Lake Winnipegosis (1881) and Treesbank (near Brandon, 1914). ${ }^{4}$ There are possibly other, more recent, Manitoba records of this species of which I am not aware.

Well Ernie didn't get any fish, but the trip was very rewarding in the finding of more rare plant species in our area. Not to mention of course the ever-rewarding experience of roaming around in our beautiful mixed woods, and enjoying the various aspects of nature.

'HARMS, V. L. 1978. Preliminary checklist of rare and potentially endangered native vascular plants of Saskatchewan. The Fraser Herbarium, Dept. of Plant Ecology, University of Saskatchewan, Saskatoon, Sask.

'LOOMAN, J., K. F. BEST. 1979. Budd's Flora. Research Branch, Agriculture Canada Publication 1662.

${ }^{3}$ MAHER, R. V., G. W. ARGUS, V. L. HARMS and J. H. HUDSON. 1979. The rare vascular plants of Saskatchewan. National Museum of Natural Sciences. Syllogeus No. 20. Ottawa, Canada.

${ }^{4}$ SCOGGAN, H. J. 1957. Flora of Manitoba. National Museum of Canada, Bulletin No. 140, Ottawa.

\section{PEACH-LEAVED WILLOWS IN SASKATCHEWAN}

DON MacPHEDRAN, 1419 - 1st St. East, Prince Albert, Saskatchewan. S6V OE6

The Prince Albert district may have the largest willow trees in Saskatchewan.

Brought up from Ontario and planted in 1895 three Peach-leaved willows (Salix amygdaloides Anderss.) have grown to huge sizes in the Prince Albert district.

Located on the farm of Tom and Mary Robins $16 \mathrm{mi}$. east of Prince Albert the largest has a spread of 82 feet and 10 inches, the second largest has a spread of 63 feet and 9 inches and the third has a spread of 55 feet and 9 inches. The largest trunk has a circumference of 11 feet measured 4 feet above ground level.

Although the Peach-leaved willow is native to Saskatchewan, it is not common.

The Prince Albert district trees are growing on sandy loam soil; they have survived many wind storms and at least one bad hailstorm. One survived a grass fire. They are now 87 years old, appear to be healthy and should survive for many years to come.

I would appreciate hearing from anyone that may know of larger trees.

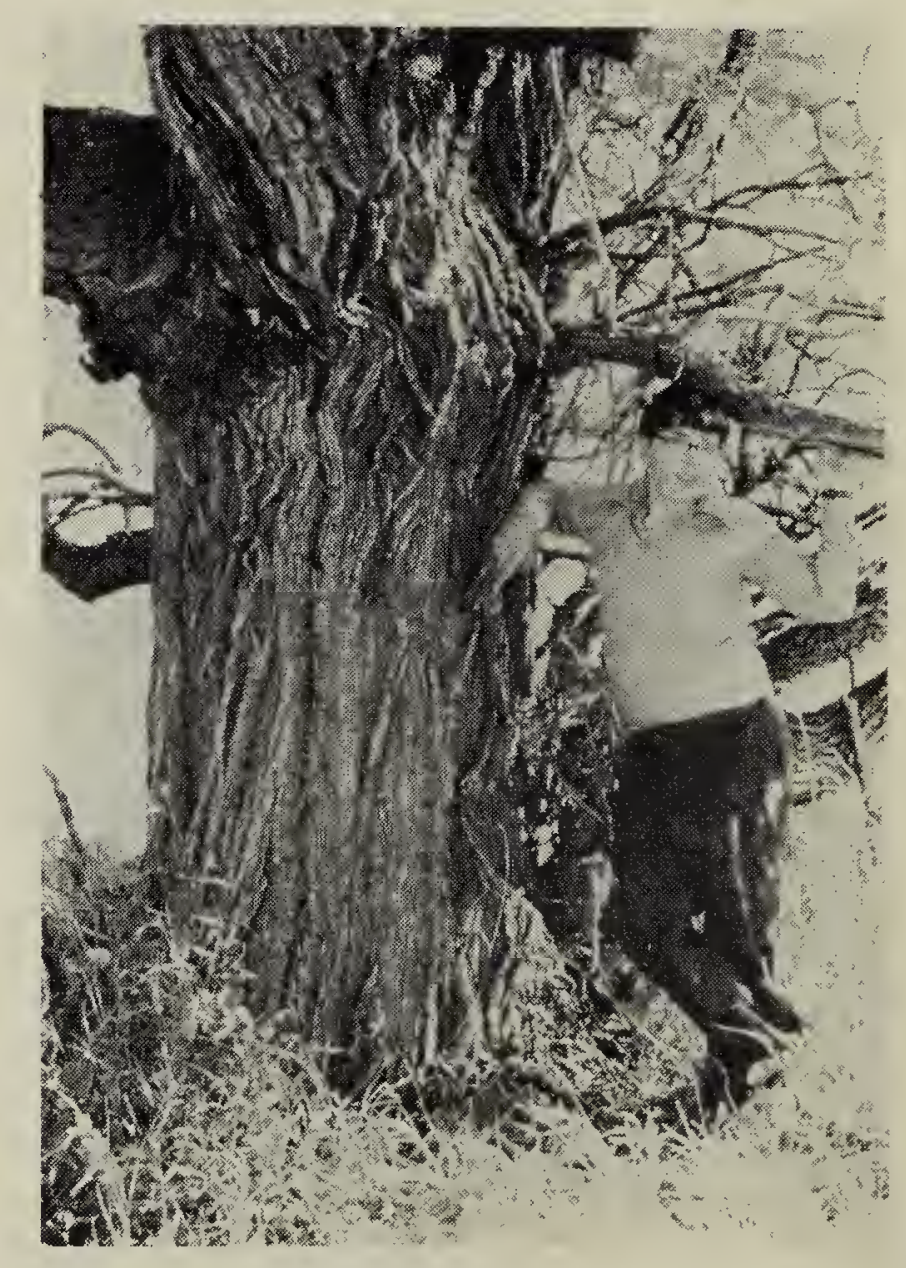

Willow with trunk circumference 11' at 4' above ground.

D. MacPhedran 


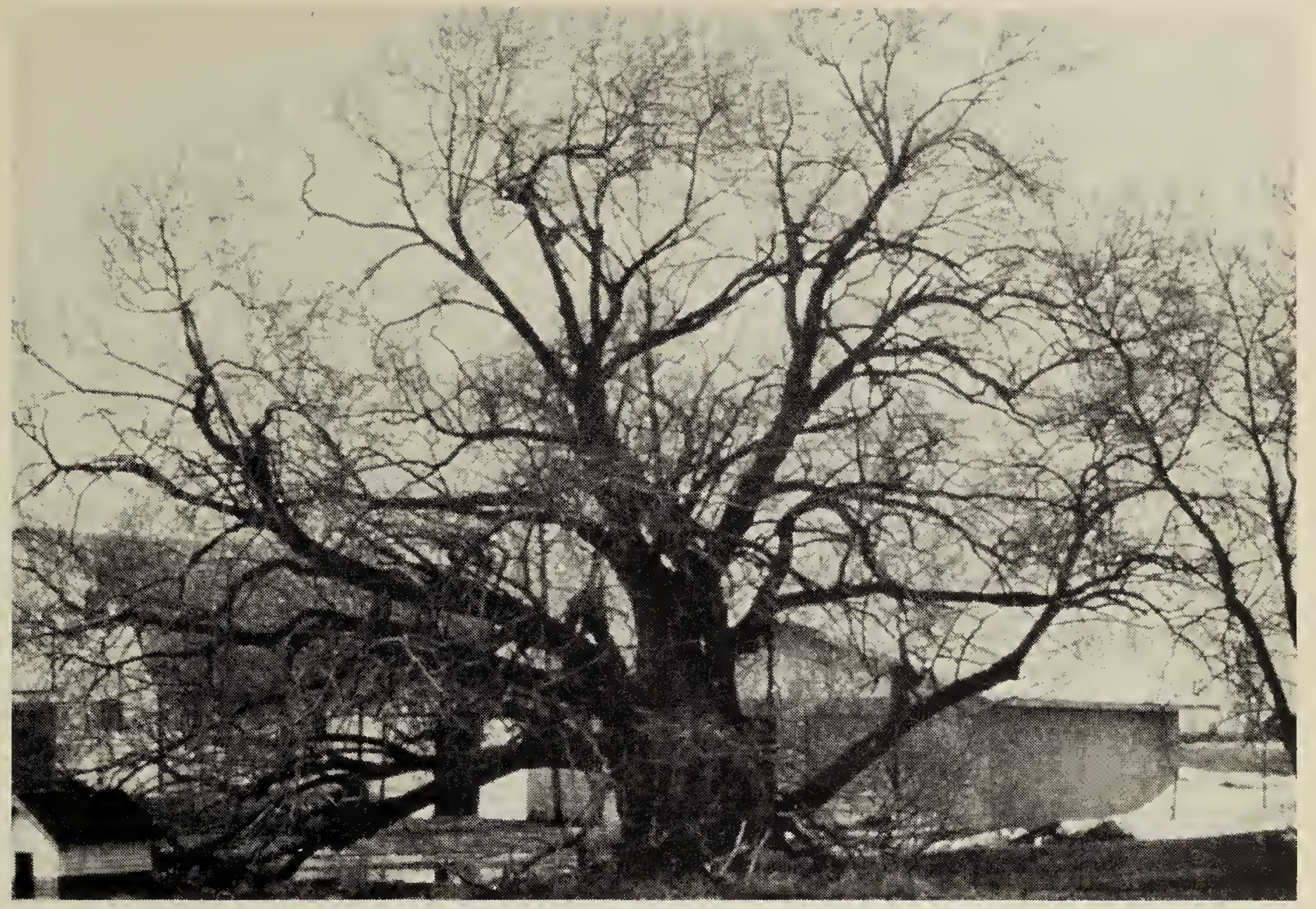

Peach-leaved Willow with spread of 82'10".

D. MacPhedran

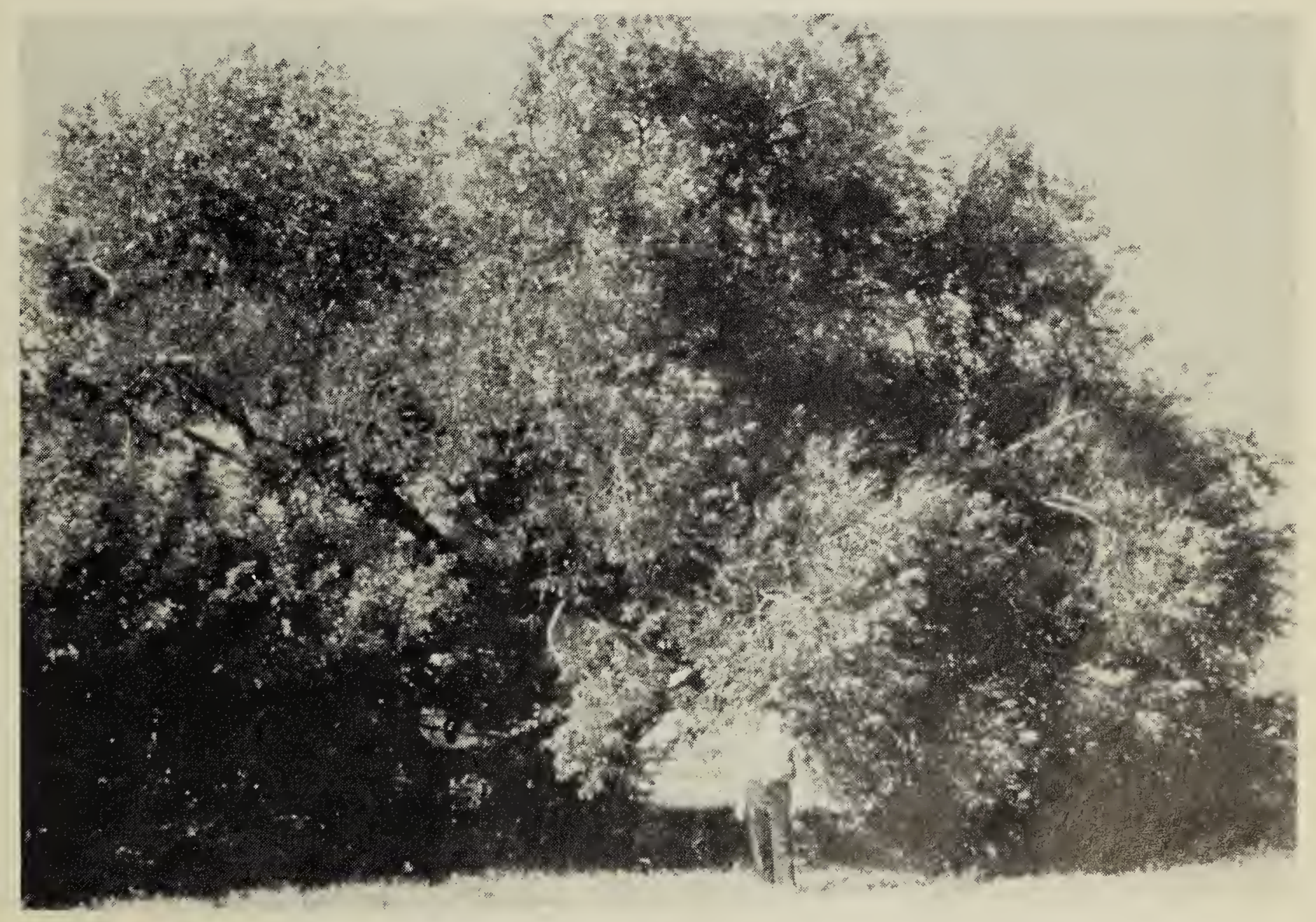

D. MacPhedran 